\title{
La ciudadanía contra sí misma en la crisis actual
}

\section{Aportes de Marcel Gauchet para identificar la limitación de cierta perspectiva liberal respecto del sujeto contemporáneo}

\author{
Raschid Rabi \\ Universidad Antonio Ruiz de Montoya
}

En una entrevista reciente, el filósofo político Marcel Gauchet señaló la paradoja actual para la ciudadanía en medio de la crisis por la pandemia padecida durante el presente ańo. Por un lado, las personas reciben el mensaje de mantener la distancia social entre sí. Por tanto, no se puede confiar ya en el otro y en su red de contactos, porque se le percibe como una potencial amenaza a los intereses personales y a los de la comunidad. Por otro lado, se promueve que debemos postergar la preocupación por cada uno de nosotros y priorizar a los demás para comprometernos en cuidarnos y así apoyarnos mutuamente, con lo cual se podrá revertir o detener, parcialmente, la actual crisis generada por la propagación de la COVID-19 ${ }^{1}$. Nunca, en nuestra historia reciente, compartimos un tipo de problemática similar a nivel global que nos regresa a una de las disyuntivas fundamentales del campo ético: ¿¿debemos priorizar el propio bienestar o el ajeno, si ambos se encuentran en conflicto, con lo cual esta disyunción se ha vuelto excluyente en algunos momentos de la presente crisis?

En este ensayo, nos interesa abordar la pregunta anterior a partir de los aportes del propio Gauchet, quien nos permitirá identificar cómo hemos llegado a este aparente conflicto de la ciudadanía contra sí misma. Ahora bien, en esta relación de opuestos entre el yo y el otro, el enfoque de nuestro autor no es ajeno a la mediación correspondiente

1 "Es un despertar de lo político", entrevista a Marcel Gauchet - recuperado de: https://lamesa.com.ar/debates/es-un-despertar-de-lo-politico-entrevista-a-marcelgauchet/\#_ednref1 
por parte del Estado respecto de este vínculo. Se identificará así un desgaste entre el principio de autoridad propio de la instancia estatal $y$, al mismo tiempo, una mayor progresión hacia la validación de los derechos individuales de cada persona, con lo cual esta tensión se hará presente detrás de la pregunta antes formulada. Habría que añadir que el surgimiento del Estado corresponde al proceso de "desencantamiento del mundo" para Gauchet durante el período axial ${ }^{2}$ con el posterior desarrollo y declive en el contexto moderno. Aunque este proceso originalmente corresponda a Max Weber, se le dará un sentido más cercano al enfoque de Emile Durkheim en su concepción de la religión al resaltar su función de integración social al interior de la comunidad humana.

\section{El Estado como resultado de la salida de la religión}

Para Gauchet, entre los siglos IX a III a. C., se dará el primer proceso de "desencantamiento del mundo con la aparición de las denominadas "religiones de trascendencia" (o de la salvación) y el surgimiento del Estado. Se establecerá una delimitación entre el orden visible y el invisible, que previamente no estaban separados. De este modo, surgirá la siguiente paradoja: el orden político y la integración social son resultado de un principio sobrenatural lejano y ajeno a este mundo y, por otra parte, las personas se someten a la autoridad del orden visible, aunque se dará, en el interior de cada uno, la posibilidad de cuestionar dicho poder, al empezar a delimitarse una esfera de autonomía para pensar la totalidad de este orden ya no como "dado", sino como querido desde la interioridad humana. En este espacio de religiones de salvación, el cristianismo proseguirá el camino desarrollado por el profetismo judío, con lo cual adquiere, por medio de Jesús mismo, la particularidad de ser la "religión de la salida de la religión". A través de él como mediación de los dos órdenes antes señalados (el visible y el invisible), se hará posible que la inmanencia de la interioridad de cada creyente se acoja al dios-trascendente totalmente otro. Hay

2 Concepto de Karl Jaspers en su obra Origen y meta de la historia. También se le traduce como el tiempo-eje. 
una adhesión desde el orden visible hacia un principio en el ámbito invisible y articulador, a su vez, de la totalidad de la realidad. En otras palabras, esta disposición hacia el principio de lo Absoluto hará posible que, desde el espacio de autonomía en el interior de la persona, se acoja la presencia ya sea de la autoridad eclesial o de la política, pero también abre la posibilidad a poder cuestionarla(s) o abandonarla(s) como ocurrirá posteriormente con el desarrollo del Estado y la ciudadanía en la modernidad. Así, se entiende mejor la denominación de la posibilidad de "salida de la religión" a partir del cristianismo.

A partir del aporte de Kantorowicz ${ }^{3}$, Gauchet considera que la mediación de Jesús hace posible que el distanciamiento frente al Absoluto del cristianismo como religión de trascedencia se torne en la apertura a la alteridad desde el interior de la persona hacia el cuerpo místico de Cristo en la institución eclesial, con lo cual se garantiza la presencia de una comunidad eterna al margen de la temporalidad de sus miembros. Esta adhesión hacia este tipo de institucionalidad eterna será la base también hacia la posterior participación del Estado, de la nación o de la sociedad civil. El poder se torna en impersonal y la trascendencia recaerá en el colectivo permanente, aunque, al mismo tiempo, una esfera de autonomía en la subjetividad de cada persona se irá desarrollando desde su interioridad, aquel espacio de encuentro con el Absoluto o de sujeción al poder del principio del orden invisible (del cosmos, de la Iglesia, del Estado o de la sociedad civil).

Las rupturas del segundo proceso de "desencantamiento del mundo" respecto del orden invisible en los inicios del mundo moderno (con las Reformas y la instauración del Estado moderno) supondrán el cierre del mundo de los seres humanos sobre sí mismos. La pugna entre el poder espiritual en su enfrentamiento con el poder imperial o monárquico significará el debilitamiento del primero y el desplazamiento del segundo hacia el colectivo del reino o de la nación, cuya representación o delegación encarnaba la máxima autoridad política, aunque las revoluciones modernas supondrán la inversión de dicho poder, cuya

3 "Los dos cuerpos del rey. Un estudio de teología política medieval” - Ernst Kantorowicz 
legitimidad ahora provendrá de cada sujeto en conjunto con el resto al expresar la voluntad general de la sociedad hacia sus representantes políticos. El poder retoma la impersonalidad propia del principio Absoluto de la religión en la antigüedad ubicado en un orden invisible. El Estado enfrentado a una comunidad de individuos se encarga de garantizar la integración social a través de la ciudadanía. Sin embargo, el principio de autoridad presente en él se encuentra en tensión con un principio de individuación en el colectivo, con lo cual el proceso de diferenciación cada vez mayor entre sí al interior de este entre sus integrantes entrará en conflicto con un sistema y burocracia estatales uniformizantes. Las normas y las leyes vigentes de este último serán, a su vez, confrontados por aquellas normativas propias de los individuos que interactúan, cada vez más, en el mercado, un orden basado en la interacción individual y que llevará, poco a poco, a prescindir de o a cuestionar la intervención estatal. Ahora bien, desde la perspectiva de la subjetividad contemporánea, el manejo de la pluralidad desplegada ante sí, más bien, paralizará o devendrá en las patologías actuales más extendidas (ansiedad, estrés, depresión, etc.), y contribuirá a esto, al mismo tiempo, en Gauchet, la presencia del inconsciente (el ámbito desplegado en la interioridad ante el vacío dejado por la salida de la religión y la mayor autonomía del individuo) en un mundo que ha perdido la presencia de las mediaciones precedentes (religión, Estado, la sociedad civil misma) para la integración social.

\section{El declive de la democracia}

A partir del proceso previamente descrito, Gauchet considera que la crisis de la democracia liberal contemporánea es la manifestación del declive de la religión en su rol por contribuir a la integración social. En los tres ejes de la salida de la religión entre los siglos XVI y XIX, estos corresponden, en primer lugar, a la consolidación de los Estados europeos entre 1500 y 1650 en el proceso de separación entre lo político y lo religioso. En segundo lugar, se encuentra la legitimación de la soberanía estatal en individualidades iguales entre sí. Se trata así de un orden querido a través del planteamiento contractualista y ya no dado como en el orden religioso anterior a la modernidad. Se produce 
así el paso de un orden anclado en la heteronomía a uno basado en la autonomía. Finalmente, en tercer lugar, la historicidad supondrá que el ser humano ya no es solo capaz de construir un nuevo orden político, sino que encargará de hacer lo propio con el mundo, la cultura, el trabajo, etc.

Este último punto será considerado por Gauchet como el "descubrimiento de la sociedad" como base de la dinámica comunitaria y el origen del cambio, con lo cual lo social se desvincula del rol integrador del Estado. El poder deja de ser así la "causa" de la sociedad y se torna, más bien, en "efecto" de la misma. Su función será "representar" a la sociedad. Gauchet llama a este proceso la "inversión liberal" que él explica como el sentido de "gobierno representativo" de la democracia moderna. A lo anterior, se suma el "hecho liberal". Es la denominación dada por nuestro autor al predominio de la sociedad civil sobre el gobierno.

Ahora bien, la primera crisis de la democracia es identificada por Gauchet con el gobierno de las élites de los regímenes parlamentarios entre 1880 y 1914 . Los parlamentos se tornan impotentes frente al tipo de problemáticas enfrentadas por la sociedad civil (la división del trabajo, los conflictos de clases sociales, etc.). Los totalitarismos y las democracias liberales serán las maneras de tratar de enfrentar esta crisis inicial. Los primeros responden a un retorno, de alguna manera, al régimen jerárquico del orden religioso como integrador de la sociedad en una perspectiva secular. Frente a ellos, las democracias liberales se expandirán como alternativa hasta la segunda crisis de los años 90 del siglo xx. En su despliegue, buscarán dar respuesta a la crisis parlamentarista a través de una reevaluación del rol del poder ejecutivo ante la problemática de la adecuada representación para que los ciudadanos se pueden identificar en su labor. Se da, a su vez, una serie de reformas administrativas para regular el posible o efectivo desorden producto del desarrollo de los mercados que se expresarán en los servicios brindados por un modelo de Estado a su población ante la enfermedad, la vejez, el paro, etc. Se produce así una integración entre el poder del Estado y el reconocimiento de los derechos de los individuos en concreto. 
Sin embargo, la crisis económica por el alza del precio del petróleo a mediados de los ańos 70 supondrá la ruptura entre el equilibrio alcanzado entre la dimensión democrática y la dimensión liberal de la autonomía individual para privilegiar, más bien, a esta última a través de las desregulaciones del Estado. La fecha emblemática de 1989 será considerada por Gauchet como el bicentenario de los logros de la revolución burguesa en Francia que han permitido entronizar al individuo del derecho (en referencia a los derechos humanos). No obstante, se producirá una nueva crisis: el pueblo soberano será remplazado por la soberanía del individuo, con lo cual la promoción del derecho democrático significará afectar a la política de la democracia.

Gauchet denominará “democracia mínima” a esta concepción que privilegia al individuo en detrimento de la pérdida de participación del colectivo y que termina basándose en un orden procedimental. De ahí, su consideración que más derechos para cada individuo significa menos poder para todos. La sociedad adopta así un funcionamiento político propio de los mercados. Los gobiernos se encargarán así de que se respeten las reglas involucradas y la marcha adecuada del proceso mismo. Ahora bien, esta crisis contemporánea abarca los cimientos mismos de la democracia moderna. Al haber surgido esta última para neutralizar cualquier poder que pudiera afectar la soberanía de los individuos, los derechos de estos son legitimados para Gauchet, pero afectan las bases propias de la democracia liberal. Para nuestro autor, la independencia individual solo adquiere pleno sentido en un gobierno en común.

Frente a la pregunta inicial del presente texto, probablemente, su formulación haya sido equívoca a partir de lo visto en los planteamientos de Gauchet. No se trata de la ciudadanía en contra de sí misma, sino, más bien, de una concepción del sujeto contemporáneo que, probablemente, se encuentre en cuestionamiento por la actual crisis de salud que reflejaría, más bien, la problemática propia de las democracias contemporáneas. En tal sentido, nuestro autor no es muy auspicioso en el corto tiempo, sino a largo plazo. Es consciente de que la crisis política aún seguirá agravándose en la actualidad, pero considera que los retos colectivos (ya sea la problemática de salud actual o la correspondiente 
a la ecología) nos llevarán a la exigencia de un mayor dominio común para enfrentar dichos desafíos. Así, un conjunto de condiciones tomadas hoy como "dadas" deberán dar paso a ser concebidas como "queridas" bajo el respectivo involucramiento de los ciudadanos ya no como individuos aislados, sino a través de la construcción de un gobierno común que responda a las mismas y permita hacerlas viables tanto para las presentes generaciones como para las futuras. Si esto último, poco a poco, se da, se habrá recuperado el tercer eje de la salida de la religión (la historicidad) que permitió, en su momento, a través de un sentido comunitario, consolidar el advenimiento del Estado moderno. 


\section{Referencias bibliográficas}

Collins, J. (2012). An Anthropological Turn? The Unseen Paradigm in Modern French Thought. New Left Review, 78. pp. 31-60.

Coniglione, F. (2013). Marcel Gauchet et les sciences humaines. Du Desechantment du monde a la crise du la democratie. Recuperado de: <https://www.yumpu.com/fr/document/view/16778825/ marcel-gauchet-et-les-sciences-humaines-francesco-coniglione>.

Gauchet, M. (2004). La democracia contra sí misma. Madrid: Homo Sapiens.

(2005). El desencantamiento del mundo. Una historia politica de la religión. Madrid: Trotta.

Gauchet, M., Wenzel-Rideout, C., \& Sass, L. (2014). The Idea of a History of the Subject. Philosophy, Psychiatry, \& Psychology 21(4), 285-298

Hewson, M. (2019). The Slow Reception of Marcel Gauchet en: <http:// journals.openedition.org/palimpsestes/4471>.

Lilla, M. (Ed.). (1994) New French Thought. Political Philosophy. Nueva Jersey: Princeton University Press.

Peden, K. The Politics of Disenchantment: Marcel Gauchet and the French Struggle with Secularization. En: <https://www.tandfonline.com/ doi/abs/10.1080/17496977.2016.1255464>. 